\title{
Treatment of Wastewater by Ozone Produced in Dielectric Barrier Discharge
}

\author{
Rita Bhatta, Rachhya Kayastha, Deepak P. Subedi, and Rajendra Joshi \\ Department of Natural Sciences, School of Science, Kathmandu University, Dhulikhel, Nepal \\ Correspondence should be addressed to Rajendra Joshi; rajendra.joshi@ku.edu.np
}

Received 19 March 2015; Revised 3 June 2015; Accepted 7 June 2015

Academic Editor: Victor David

Copyright ( 2015 Rita Bhatta et al. This is an open access article distributed under the Creative Commons Attribution License, which permits unrestricted use, distribution, and reproduction in any medium, provided the original work is properly cited.

\begin{abstract}
There is rapid diminishing of water resources in many countries due to, for example, population growth and constant reduction in fresh water supply. The sewage wastewater, industrial effluents, and municipal wastewater are directly and indiscriminately discharged into rivers and lakes and thus primarily cause water pollution in Nepal. This has increased the water crisis and also causes environmental deterioration. Therefore, the need for the development of an effective, cheap, and environmentally friendly process for the treatment of wastewater before discharging into aquatic environment has emerged. Treatment by ozone produced from dielectric barrier discharge is one of the emerging technologies for such application. The ozonation process is more effective for disinfection and degradation of organic pollutants from water. The current study describes the treatment of wastewater of selected site within Kathmandu. Results on various physicochemical and microbial parameters of the inlet and outlet samples are discussed. Our results showed slight increase in $\mathrm{pH}$, decrease in chemical oxygen demand, and significant increase in dissolved oxygen after ozonation. Importantly, ozonation caused total reduction of fecal coliform.
\end{abstract}

\section{Introduction}

Water pollution and also freshwater depletion because of inappropriate discharge of polluted effluents from agricultural, industrial, and domestic sewage activities are some of the major factors that contribute to environmental issues in Nepal [1]. The increasing pace of urbanization and human activities especially in developing countries continues to affect the quality and quantity of freshwater detrimentally. As such, there is urgent need for suitable methods of wastewater treatment $[2,3]$. The sewage wastewater, industrial effluents, and municipal wastewater are directly and indiscriminately discharged into rivers and lakes which is the primary cause of water pollution in Nepal. This has increased the water crisis and also deteriorated the environment $[3,4]$. Besides water crisis, water pollution can also be a source of air pollution through evaporation even into our homes causing various effects for example on health and materials $[5,6]$. Water pollution, especially surface water, in developing countries has become more severe and critical with rapid urbanization and lack of adequate sanitation [7]. Usable water should exhibit certain parameters (physicochemical and biological) within an acceptable range. In order to meet this demand, water treatment is needed in some cases and various methods are already in practice. One of the emerging technologies in our context is to use ozone produced by dielectric barrier discharge. Reports on ozone treatment for water and/or wastewater are already published [8-10]. Ozonation processes are replacing conventional chlorination processes because of its stronger oxidizing nature and effective disinfectant property without any side effects [11, 12]. Ozone dispersion in water is accompanied by two basic processes, oxidation and disinfection [13].

Ozone can be produced by various ways and in the current study a dielectric barrier discharge (DBD) technique was used. DBD has numerous applications such as ozone production, surface modification, material processing, biological decontamination, pollution control by oxidation of volatile organic compound or nitrogen monoxide, UV or vacuum ultra-violet (VUV) generation, aerosol charging, and electrofiltration, and one of its important application is the treatment of potable water and wastewater $[14,15]$.

In a $\mathrm{DBD}$ reactor the electrical discharge takes place between electrodes where at least one of the electrodes is 


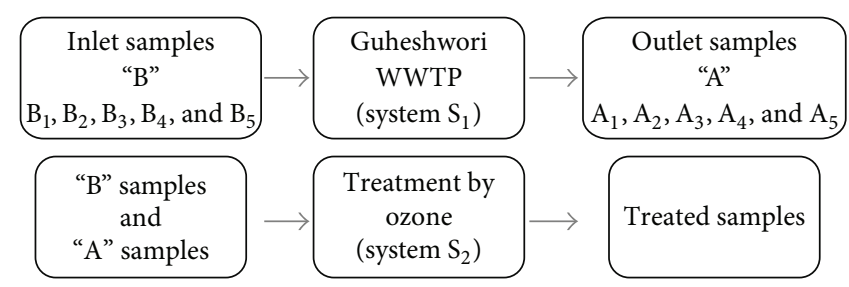

FIGURE 1: Schematic scheme of sampling and treatment of wastewater.

covered with a thin layer of dielectric material. The dielectric material used is a type of insulator and is made of ceramic, glass, PVC, and so forth. When an AC voltage is applied across the electrode, discharge is generated with the production of UV. The discharge is usually organized through a large number of filamentary channels of streamers, $100-200 \mu \mathrm{m}$ in diameter [12].

When air is passed through the DBD under the influence of high energy electrons within the interelectrode space, the dissociation of oxygen molecules occurs. The atomic oxygen combines with another oxygen molecule to form a strong oxidizing agent that is ozone:

$$
\begin{aligned}
& \mathrm{O}_{2} \longrightarrow \mathrm{O}^{*}+\mathrm{O}^{*} \\
& \mathrm{O}^{*}+\mathrm{O}_{2} \longrightarrow \mathrm{O}_{3}
\end{aligned}
$$

In addition to ozone, electric discharge in air produces variety of chemically active species, such as $\mathrm{OH}^{-}, \mathrm{NO}, \mathrm{O}_{3}{ }^{*}, \mathrm{~N}_{2}{ }^{*}$, $\mathrm{N}^{*}, \mathrm{OH}^{*}, \mathrm{O}_{2}{ }^{+}, \mathrm{N}_{2}{ }^{+}$, and $\mathrm{O}^{+}$. These species are short-lived and decay before ozone enriched air gets into the water. Ozone, thus produced, is released into the water where it oxidizes various organic and inorganic chemicals present in water and converts them into simpler form which gets easily decomposed in the nature [11].

The main objective of the current study is to carry out treatment of wastewater by ozone produced in dielectric barrier discharge and to evaluate the different parameters. The results will be more interesting where wastewater is of similar quality and is generated in analogous way. Thus, these findings will ultimately be helpful to improve the quality of wastewater. This research was conducted at Kathmandu University from 2013 to 2014.

\section{Materials and Methods}

The wastewater samples were collected from Guheshwori wastewater treatment plant (WWTP) located at Guheshwori, Kathmandu, the capital city of Nepal. Sampling was done in two seasons, that is, before monsoon (May 10, 2013) and after monsoon (October 27, 2013). Sample preservation was done according to United States Environmental Protection Agency (USEPA) sample preservation guidelines. Samples were collected in different plastic bottles using different preservatives depending upon the parameter intended to be tested. Water samples were collected from the inlet (B) and outlet (A) of WWTP. After collection the samples were brought into the Plasma Laboratory of Kathmandu University where they were treated by ozone produced in

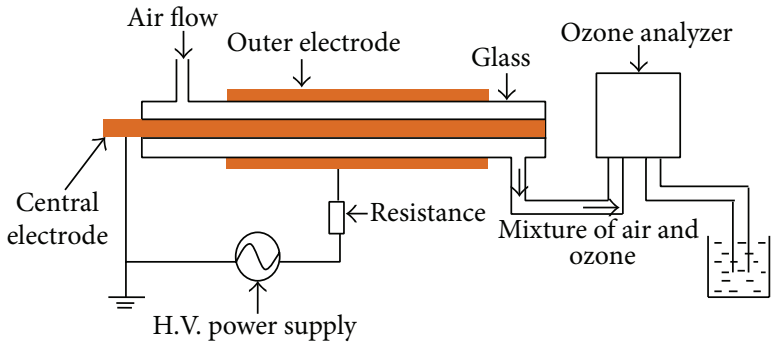

FIGURE 2: Experimental setup of DBD system for the ozone generation.

dielectric barrier discharge (DBD). As depicted in Figure 1, five replicates of inlet to WWTP were named $B_{1}-B_{5}$ and outlet samples $A_{1}-A_{5}$. Replicates of both $B$ and $A$ samples were treated by ozone. System $S_{1}$ refers to Guheshwori WWTP whereas $S_{2}$ refers to ozone treatment.

Different physicochemical parameters were analyzed in the chemistry laboratory and microbial parameter in the microbiology laboratory of Kathmandu University. Heavy metals like lead, cadmium, and chromium were analyzed in Environment and Public Health Organization (ENPHO) laboratory, Kathmandu. Different physicochemical and microbial parameters of the inlet (B), outlet (A), and ozone treated samples were compared after analysis.

Discharge from dielectric barrier was generated using high voltage AC power supply operating at $50 \mathrm{~Hz}$. The electrode system was coaxial cylindrical in type. The anode was connected to the central rod made of brass placed inside the tube and cathode was connected by sheet of aluminum shielded outside of the tube. The thickness of glass was $1 \mathrm{~mm}$. The gas passed inside the tube through the gap between the anode and the glass tube. It was supplied by air pump (ATEC Aquarium, AR-8500). The flow rate of air was $4 \mathrm{~L} / \mathrm{min}$. The concentration of ozone produced was measured by an ozone analyzer (Ozone Analyzer BMT 964, Messtechnik GmbH, Germany). The specification of the DBD system is given below.

Diameter of brass rod is $8 \mathrm{~mm}$, length of outer electrode and central electrode is $15 \mathrm{~cm}$ and $23 \mathrm{~cm}$ respectively, thickness of dielectric (glass) is $1 \mathrm{~mm}$, internal diameter of glass is $10 \mathrm{~mm}$, and thickness of aluminum sheet is $0.5 \mathrm{~mm}$. The experimental setup used for ozone generation in this study is shown in Figure 2.

The wastewater samples $(100 \mathrm{~mL})$ were treated for 20 minutes at a voltage $19.5 \mathrm{kV}$. The concentration of ozone was 
TABLE 1: Test parameters and their test methods.

\begin{tabular}{|c|c|c|}
\hline Parameters & Unit & Test methods \\
\hline $\mathrm{pH}$ & - & $\mathrm{pH}$ meter \\
\hline Conductivity & $\mu \mathrm{s} / \mathrm{cm}$ & Conductivity meter \\
\hline TDS & $\mathrm{mg} / \mathrm{L}$ & Calibrated EC-TDS meter \\
\hline Nitrate & $\mathrm{mg} / \mathrm{L}$ & UV Vis spectrophotometer-304 nm \\
\hline COD & $\mathrm{mg} / \mathrm{L}$ & Titration using potassium dichromate \\
\hline $\mathrm{DO}$ & $\mathrm{mg} / \mathrm{L}$ & DO meter \\
\hline Fecal coliform & $\mathrm{CFU} / 100 \mathrm{~mL}$ & Membrane filtration method \\
\hline Ferrous & $\mathrm{mg} / \mathrm{L}$ & UV Vis spectrophotometer- $515 \mathrm{~nm}$ \\
\hline Chromium & $\mathrm{mg} / \mathrm{L}$ & Atomic absorption spectrophotometer \\
\hline Cadmium & $\mathrm{mg} / \mathrm{L}$ & Atomic absorption spectrophotometer \\
\hline Lead & $\mathrm{mg} / \mathrm{L}$ & Atomic absorption spectrophotometer \\
\hline
\end{tabular}

nearly $800 \mathrm{ppm}$ at this voltage. Ozone was homogeneously bubbled into the sample with the help of spherical porous air stone.

Analyzed parameters with their unit and test methods are mentioned in Table 1. Standard test methods were followed for analysis. Ferrous and other heavy metals were tested as reported elsewhere [16].

Descriptive statistics was used for data analysis. Mean and standard deviation were used for calculation. Paired $t$-test was done to check if the mean values were significantly different.

\section{Results and Discussion}

Different physicochemical and microbial parameters of inlet and outlet samples from Guheshwori WWTP were analyzed before and after treatment by ozone for two seasons (premonsoon and postmonsoon). In premonsoon season, the amount of water is low by which pollutants are more concentrated in the samples whereas in postmonsoon season washing off of solid might take place and thus there will be dilution of organic and inorganic pollutants. The following parameters were tested.

3.1. Fecal Coliform. The experimental result of fecal coliform analysis is shown in Figure 3. For premonsoon sampling, the mean value of coliform formation unit per $100 \mathrm{~mL}$ of fecal coliform of 5 replicates of inlet (B) and outlet (A) samples from Guheshwori WWTP is found to be $148 \times 10^{7}$ and $48 \times$ $10^{7}$, respectively. After treatment by ozone the fecal coliform reduced to nil. Likewise, for postmonsoon sampling, the mean value of fecal coliform for B samples and A samples is $22.8 . \times 10^{7}$ and $19.6 \times 10^{7}$, respectively. Here, also after treatment by ozone fecal coliform reduced to zero.

3.2. Color. Inlet (B) samples from the system $S_{1}$ were dark grey colored while outlet samples (A) were light grey colored. When the samples were treated by ozone (system $\mathrm{S}_{2}$ ) color changed to light. In both cases, examination of the color was done visually. Similar results of decolorization of the samples were observed by Gharbani et al. [17] in which ozonation process enhanced degradation of the products.

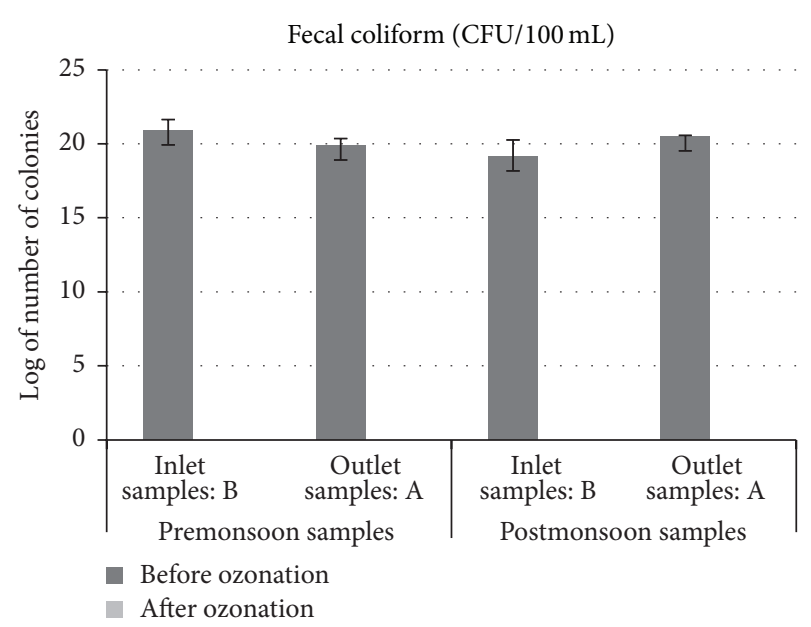

FIGURE 3: Fecal coliform of inlet and outlet samples before and after treatment by ozone. After ozonation, fecal coliform reduced to zero.

3.3. Dissolved Oxygen (DO) ( $m g / L)$. For premonsoon sampling, the mean value of dissolved oxygen for five replicates of inlet samples (B) and outlet samples (A) from system $\mathrm{S}_{1}$ is found to be 0.72 and 4.36 , respectively. After treatment by ozone, the mean DO values are 9.41 and 9.55 , respectively, for B and A samples. Similarly, for postmonsoon sampling, the mean value of dissolved oxygen for five replicates of inlet samples (B) and outlet samples (A) from system $S_{1}$ is found to be 1.1 and 4.3 , respectively. After treatment by ozone the mean DO values are 8.6 and 9.5, respectively, for B and A samples. From the above data it is clear that the value of DO increased after treatment by system $S_{1}$ but this DO value is not enough to sustain aquatic life. Minimum DO level required for protection of aquatic life is 5.8 to $6.8 \mathrm{mg} / \mathrm{L}$ [18]. Importantly, as shown in Figure 4, after treatment by ozone (system $\mathrm{S}_{2}$ ) the DO level increased significantly and reached up to 9.55 .

3.4. $p H$. The mean value of $\mathrm{pH}$ of inlet samples (B) and outlet samples (A) from system $\mathrm{S}_{1}$ is found to be 6.97 and 7.74, respectively, for premonsoon season and 7.25 and 7.56, 


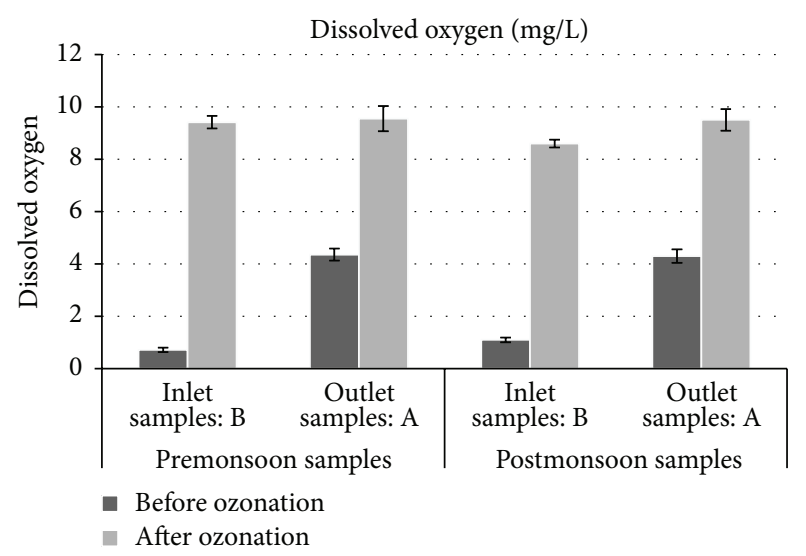

Figure 4: Dissolved oxygen of inlet and outlet samples before and after treatment by ozone.

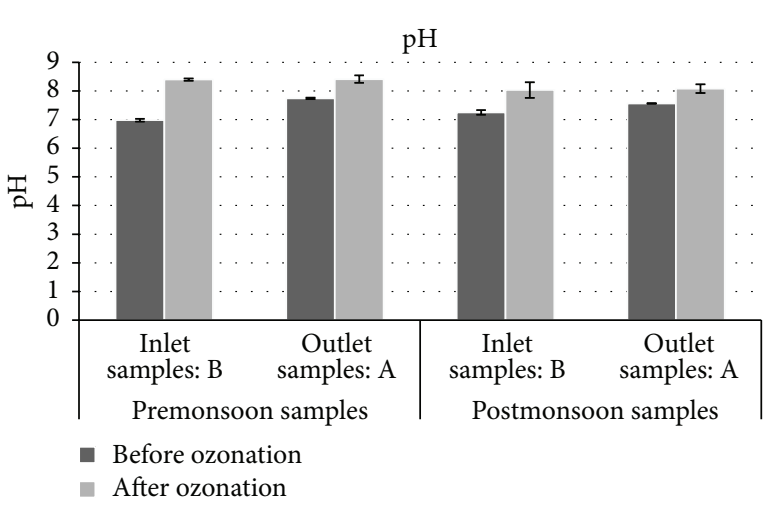

FIGURE 5: $\mathrm{pH}$ of inlet and outlet samples before and after treatment by ozone.

respectively, for postmonsoon season. As shown in Figure 5, after ozonation the mean value of $\mathrm{pH}$ is 8.39 and 8.41 , respectively, for inlet and outlet samples for premonsoon season and 8.03 and 8.08, respectively, for postmonsoon samples which indicates slight increase in $\mathrm{pH}$ after ozonation. Subedi et al. [19] has also reported no significant change to marginal increment of $\mathrm{pH}$ after ozonation.

3.5. Electrical Conductivity $(\mu \mathrm{S} / \mathrm{cm})$. For premonsoon sampling, the mean value of conductivity for five replicates of inlet (B) and outlet (A) samples before ozone treatment is found to be 1380.80 and 1263.60, respectively. After treatment by ozone, the mean conductivity values are 1423.75 and 1295.25 for B and A samples, respectively. Similarly, for postmonsoon sampling, the mean value of conductivity of inlet (B) and outlet (A) samples before ozonation is found to be 1349.20 and 966.8 , respectively. After treatment by ozone the mean conductivity values are 1485.20 and 994.25 for B and A samples, respectively. These results are shown in Figure 6 and indicate that electrical conductivity did not change significantly after ozonation $(p>0.01)$.

3.6. Total Dissolved Solid (TDS) ( $m g / L)$. The mean value of TDS of inlet samples (B) and outlet samples (A) from

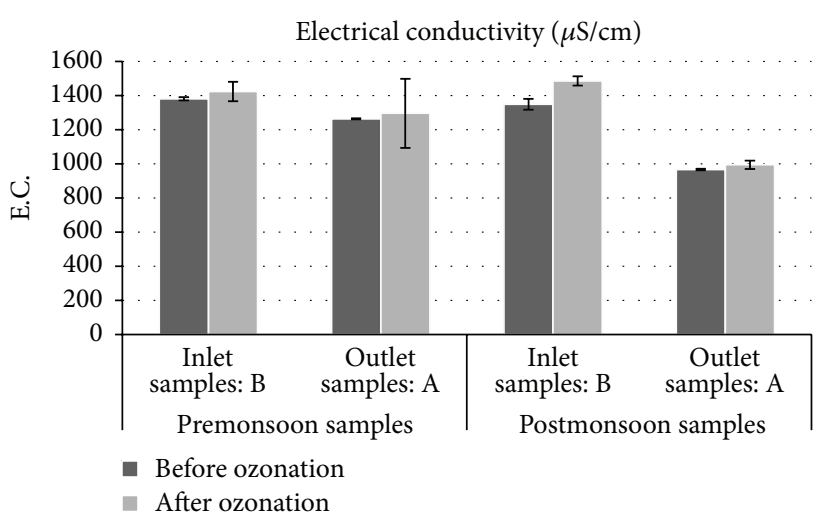

FIGURE 6: Electrical conductivity of inlet and outlet samples before and after treatment by ozone.

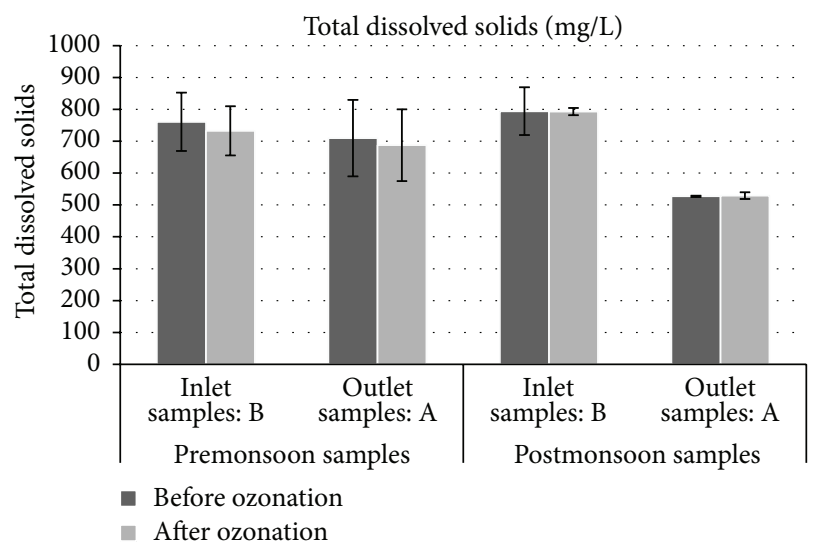

FIGURE 7: Total dissolved solids of inlet and outlet samples before and after treatment by ozone.

system $S_{1}$ is found to be 760.50 and 709.25 , respectively, for premonsoon season and 794.00 (B) and 527.20 (A) for postmonsoon season. After treatment by ozone, the mean TDS values are 732.25 and 687.50, respectively, for B and A samples of premonsoon season and 792.80 and 529.25, respectively, for postmonsoon season. There was not any significant difference in total dissolved solids after ozonation $(p>0.05)$. The TDS values are shown in Figure 7.

3.7. Chemical Oxygen Demand (COD) $(m g / L)$. The mean value of COD of inlet and outlet samples from system $S_{1}$ was found to be 368.8 and 43.6, respectively. After ozonation these values decreased significantly to 275.2 and 31.9 , respectively (Figure 8). This result indicates the presence of series of chain reactions initiated by ozone dissolved in water which in turn fragmentize large organic molecules in water and thus decrease COD [14].

3.8. Nitrate $(m g / L)$. For premonsoon season, the mean value of nitrate of inlet samples (B) and outlet samples (A) from system $S_{1}$ is found to be 6810 and 4330, respectively. After treatment by ozone, the mean nitrate values are 7250 and 13310 for B and A samples, respectively. Similarly, for 


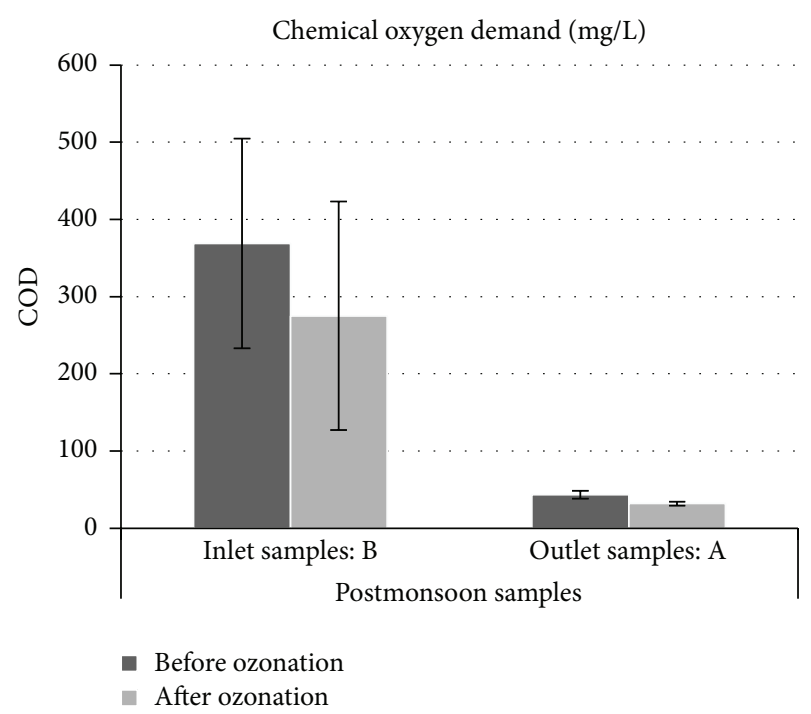

Figure 8: Chemical oxygen demand of inlet and outlet samples before and after treatment by ozone.

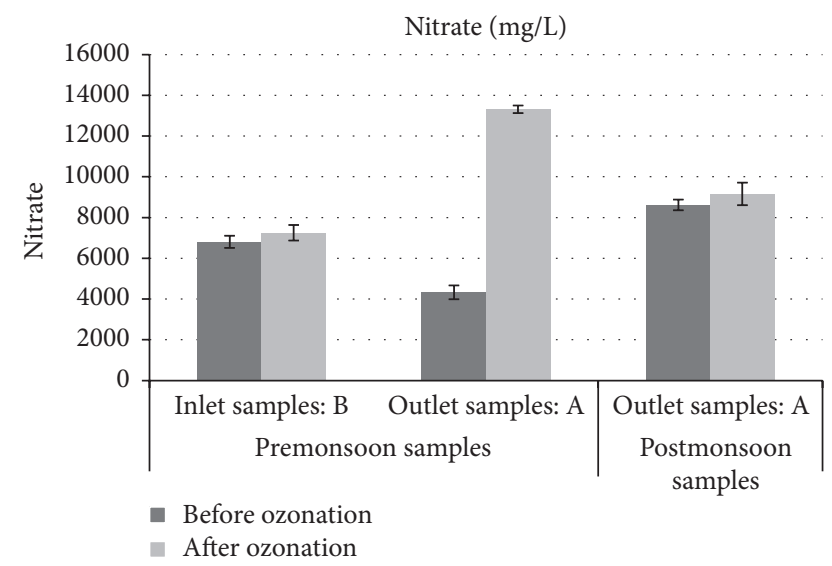

FIGURE 9: Nitrate concentration of inlet and outlet samples before and after treatment by ozone.

postmonsoon sampling, the mean value of nitrate of outlet samples from system $S_{1}$ is found to be 8620 . After treatment by ozone, the mean nitrate value is 9160 for outlet samples (A) (Figure 9).

Nitrate concentration increased after ozonation. It is because ozonation oxidizes some organic nitrogen into ammonia and nitrite ion into nitrate ion [20]. Also, ozone converts nitrite or other nitrogenous compounds in the water into nitrate by direct oxidation [19].

3.9. Ferrous $(m g / L)$. The mean ferrous value of inlet samples (B) and outlet samples (A) from system $S_{1}$ is found to be 1.14 and 0.65 , respectively, for premonsoon season, and for postmonsoon season it is 0.63 and 0.30 , respectively. After treatment by ozone, the mean ferrous values are 1.03 and 0.65 , respectively, for $\mathrm{B}$ and $\mathrm{A}$ samples for premonsoon season and for postmonsoon season 0.58 (B) and 0.29 (A) are observed (Figure 10). Ferrous concentration decreased after ozonation.

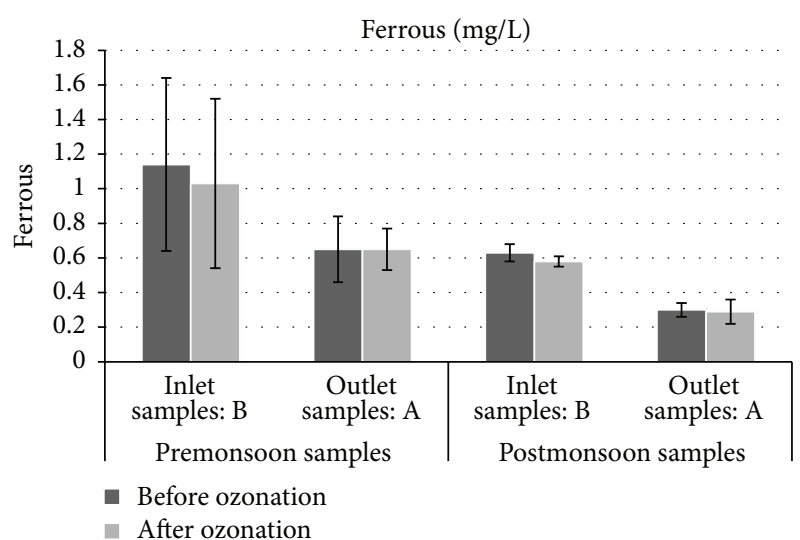

FIgURE 10: Ferrous concentration of inlet and outlet samples before and after treatment by ozone.

Similar results of reduction of ferrous concentration after ozonation was reported by Subedi et al. [19].

3.10. Lead $(m g / L)$. Inlet samples before ozone treatment showed the mean value of lead concentration as 0.036 . After treatment, concentration of lead could not be detected indicating the reduction in concentration.

3.11. Cadmium $(\mathrm{mg} / \mathrm{L})$. Only two replicates of inlet samples showed cadmium concentration (0.02 and 0.01) and, after treatment by ozone, cadmium concentration could not be detected indicating the reduction in the concentration below the detection limit of the instrument $(<0.003 \mathrm{mg} / \mathrm{L})$.

3.12. Chromium $(m g / L)$. The mean value of inlet samples from system $S_{1}$ for chromium concentration is 0.058 . In the outlet samples the chromium is not detected. After treatment by ozone, chromium is not detected in two samples of the replicates. The average value of three replicates is 0.03 .

The concentration of lead, cadmium, and chromium is depicted in Table 2.

\section{Conclusion}

Ozone was produced by DBD and its concentration was nearly $800 \mathrm{ppm}$ in 5 minute treatment time at $19.5 \mathrm{kV}$. Ozone increases DO remarkably and reduces fecal coliform to zero and thus showed very good disinfectant nature. Ozone lightens the color of wastewater, decreases COD, and increases $\mathrm{pH}$ slightly. There is not any significant change in electrical conductivity and total dissolved solid. Nitrate concentration increased after ozonation. Ferrous concentration decreased and concentration of other heavy metals as lead, cadmium, and chromium is found to be less than detection limit. Further, we are planning to investigate the relation between concentration of ozone released from dielectric barrier discharge, time of treatment, and effect on different parameters. 
TABLE 2: Concentrations of lead, cadmium, and chromium before and after treatment by ozone.

\begin{tabular}{|c|c|c|c|c|c|c|}
\hline \multirow{2}{*}{ Sample ID } & \multicolumn{2}{|c|}{ Lead } & \multicolumn{2}{|c|}{ Cadmium } & \multicolumn{2}{|c|}{ Chromium } \\
\hline & Before ozonation & After ozonation & Before ozonation & After ozonation & Before ozonation & After ozonation \\
\hline $\mathrm{B}_{1}$ & 0.07 & $\mathrm{ND}(<0.01)$ & 0.02 & $\mathrm{ND}(<0.003)$ & 0.03 & 0.04 \\
\hline $\mathrm{B}_{2}$ & 0.05 & ND & 0.01 & ND & 0.09 & 0.03 \\
\hline $\mathrm{B}_{3}$ & 0.02 & ND & ND & ND & 0.06 & $\mathrm{ND}(<0.02)$ \\
\hline $\mathrm{B}_{4}$ & 0.02 & ND & ND & ND & 0.06 & ND \\
\hline $\mathrm{B}_{5}$ & 0.02 & ND & ND & ND & 0.05 & 0.02 \\
\hline $\mathrm{A}_{1}-\mathrm{A}_{5}$ & ND & ND & ND & ND & ND & ND \\
\hline
\end{tabular}

ND: not detected.

\section{Conflict of Interests}

The authors declare that there is no conflict of interests regarding the publication of this paper.

\section{Acknowledgments}

The authors would like to thank Ms. Sangita Shrestha for her help in microbial analysis of wastewater samples. This research was supported by the International Foundation for Science (IFS), Stockholm, Sweden, and the Organization for the Prohibition of Chemical Weapons, The Hague, The Netherlands, through Grant no. W/4373-2. Also, financial support of University Grants Commission, Nepal (069/070), is gratefully acknowledged.

\section{References}

[1] ADB, Country Environment Analysis for Nepal, Asian Development Bank, Kathmandu, Nepal, 2004.

[2] I. Bruch, J. Fritsche, D. Bänninger et al., "Improving the treatment efficiency of constructed wetlands with zeolite-containing filter sands," Bioresource Technology, vol. 102, no. 2, pp. 937-941, 2011.

[3] A. Gurung and O. Sang-Eun, "An overview of water pollution and constructed wetlands for sustainable wastewater treatment in Kathmandu Valley," Scientific Research and Essays, vol. 7, no. 11, pp. 1185-1194, 2012.

[4] R. R. Shrestha, R. Haberl, J. Laber, R. Manandhar, and J. Mader, "Application of constructed wetlands for wastewater treatment in Nepal," Water Science and Technology, vol. 44, no. 11-12, pp. 381-386, 2001.

[5] C. Tzanis, C. Varotsos, J. Christodoulakis et al., "On the corrosion and soiling effects on materials by air pollution in Athens, Greece," Atmospheric Chemistry and Physics, vol. 11, no. 23, pp. 12039-12048, 2011.

[6] J. Tidblad, V. Kucera, M. Ferm et al., "Effects of air pollution on materials and cultural heritage: ICP materials celebrates 25 years of research," International Journal of Corrosion, vol. 2012, Article ID 496321, 16 pages, 2012.

[7] M. S. Kambole, "Managing the water quality of the Kafue river," Physics and Chemistry of the Earth, vol. 28, no. 20-27, pp. 11051109, 2003.

[8] J. Sarasa, M. P. Roche, M. P. Ormad, E. Gimeno, A. Puig, and J. L. Ovelleiro, "Treatment of a wastewater resulting from dyes manufacturing with ozone and chemical coagulation," Water Research, vol. 32, no. 9, pp. 2721-2727, 1998.
[9] W. H. Glaze, J.-W. Kang, and D. H. Chapin, "The chemistry of water treatment processes involving ozone, hydrogen peroxide and ultraviolet radiation," Ozone: Science \& Engineering, vol. 9, no. 4, pp. 335-352, 1987.

[10] R. G. Rice, "Application of ozone for industrial wastewater treatment-a review," Ozone: Science \& Engineering, vol. 18, no. 6, pp. 477-515, 1996.

[11] M. A. Malik, A. Ghaffar, and S. A. Malik, "Water purification by electrical discharges," Plasma Sources Science and Technology, vol. 10, no. 1, pp. 82-91, 2001.

[12] M. M. Kuraica, B. M. Obradović, D. Manojlović, D. R. Ostojić, and J. Purić, "Ozonized water generator based on coaxial dielectric-barrier-discharge in air," Vacuum, vol. 73, no. 3-4, pp. 705-708, 2004.

[13] N. D. Chichirova and I. V. Evgeniev, "Technology of ozonization of water and filtering media in heat-and-power engineering," Butlerov Communications, vol. 2, pp. 27-31, 1999.

[14] D. P. Subedi, R. B. Tyata, A. Khadgi, and C. S. Wong, "Treatment of water by dielectric barrier discharge," Journal of Science and Technology in the Tropics, vol. 5, no. 2, pp. 117-123, 2009.

[15] R. B. Tyata, D. P. Subedi, and C. S. Wong, "Comparison of dielectric barrier discharge in air, nitrogen and argon at atmospheric pressure," Kathmandu University Journal of Science, Engineering and Technology, vol. 6, no. 2, pp. 6-12, 2010.

[16] L. Clesceri, A. Greenberg, R. R. Trussell et al., Standard Methods for the Examination of Water and Wastewater, American Public Health Association, American Water Works Association, Water Pollution Control Federation, 17th edition, 1989.

[17] P. Gharbani, S. M. Tabatabaii, and A. Mehrizad, "Removal of Congo red from textile wastewater by ozonation," International Journal of Environmental Science \& Technology, vol. 5, no. 4, pp. 495-500, 2008.

[18] P. K. Goel, Water Pollution Causes, Effects and Control, New Age International, 2nd edition, 2006.

[19] D. P. Subedi, R. B. Tyata, A. Khadgi, and C. S. Wong, "Physicochemical and microbiological analysis of drinking water treated by using ozone," Sains Malaysiana, vol. 41, no. 6, pp. 739-745, 2012.

[20] B. Wang, J. Tian, J. Yin, and G. Shi, "Ammonia, nitrite and nitrate nitrogen removal from polluted source water with ozonation and BAC processes," Ozone: Science \& Engineering, vol. 11, no. 2, pp. 227-244, 1989. 

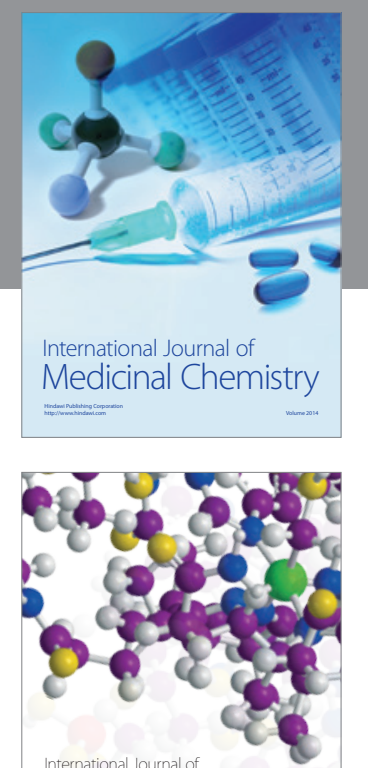

\section{Carbohydrate} Chemistry

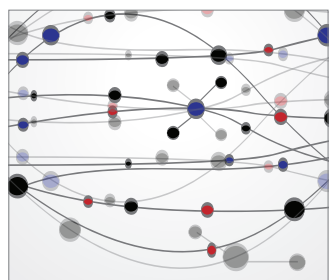

The Scientific World Journal
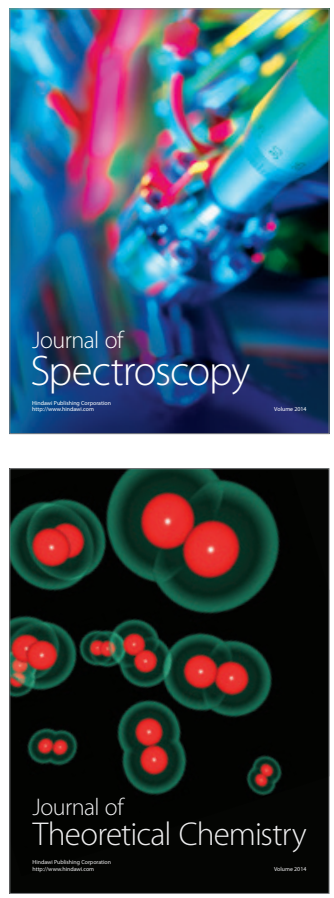
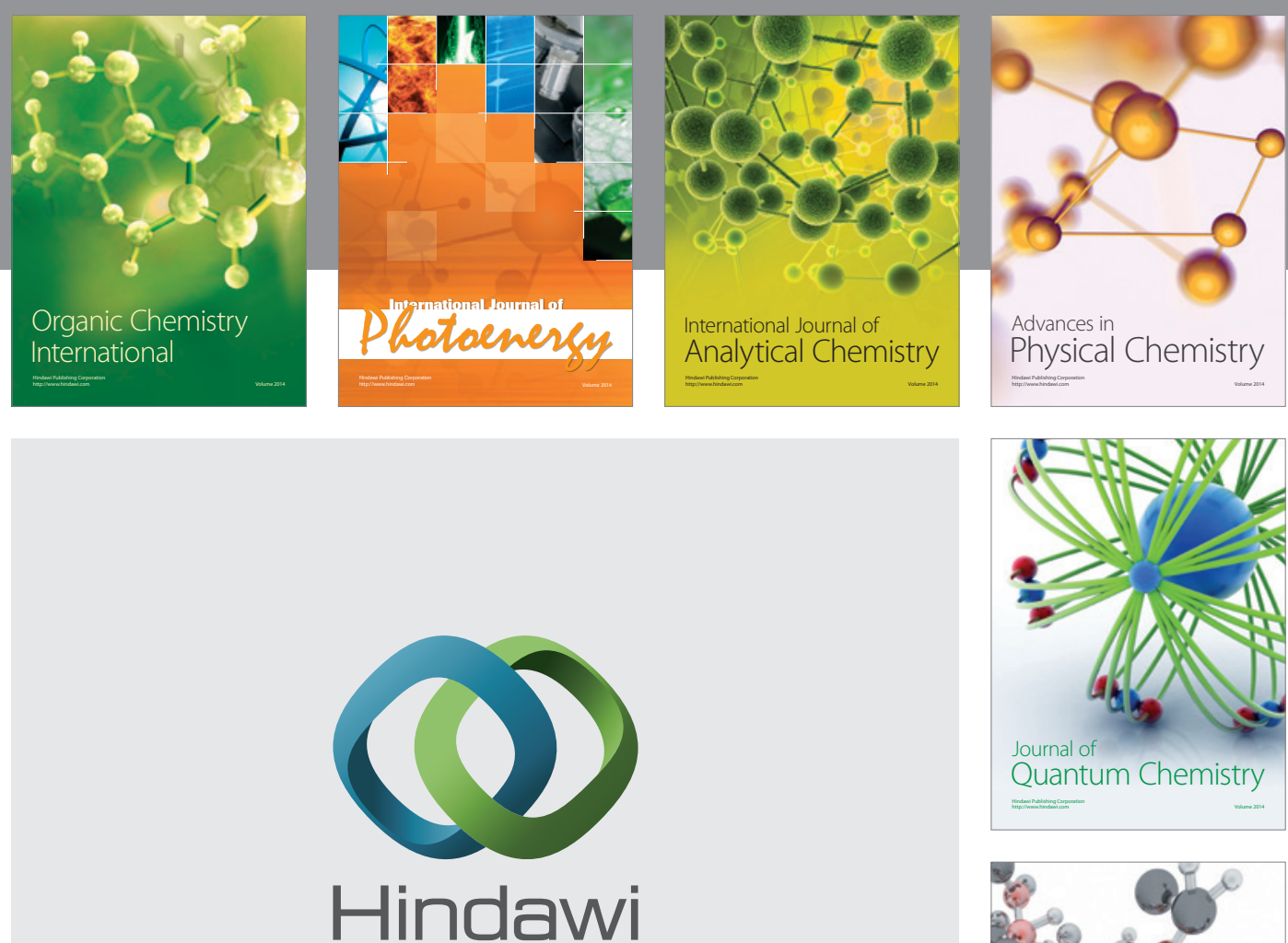

Submit your manuscripts at

http://www.hindawi.com

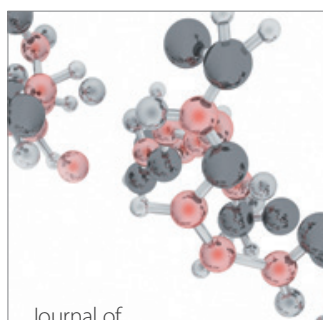

Analytical Methods

in Chemistry

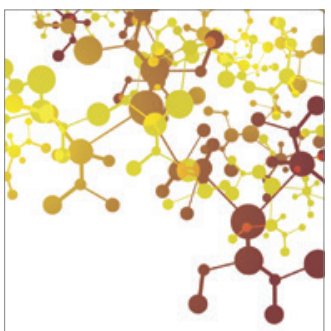

Journal of

Applied Chemistry

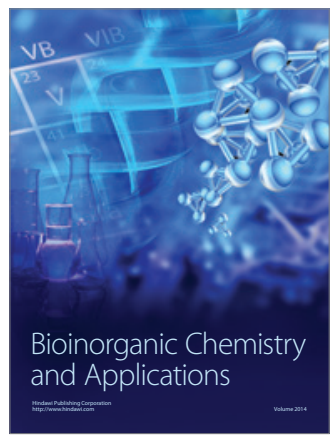

Inorganic Chemistry
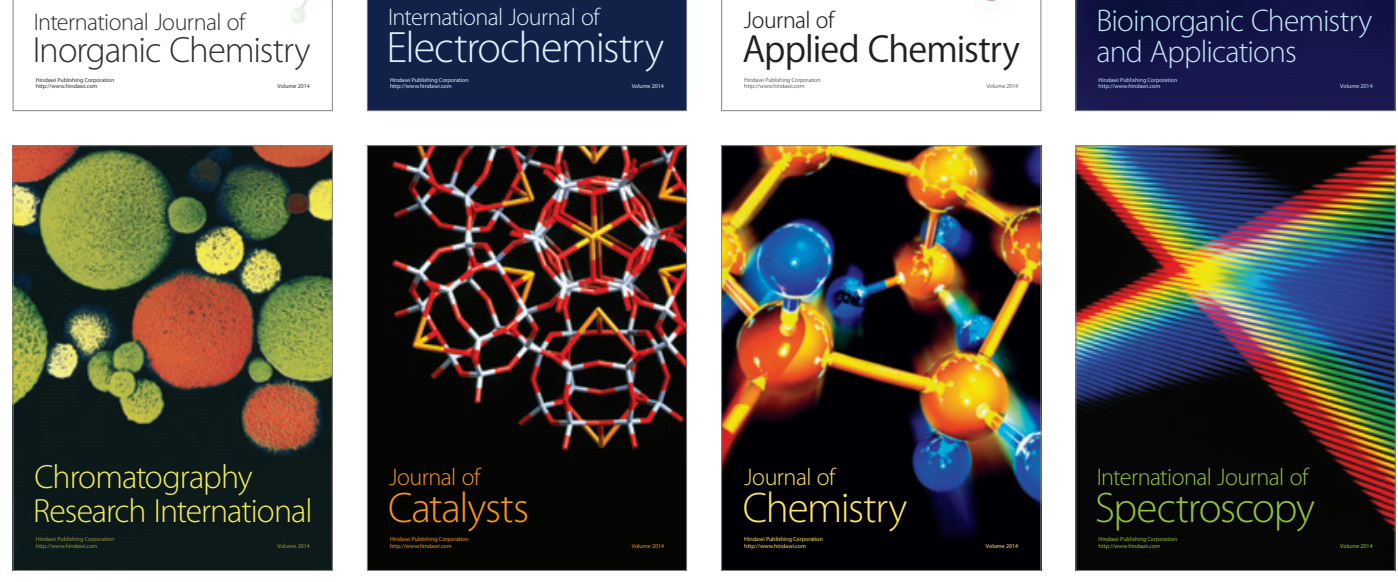